\title{
Filter revamping, the economic way to get old filters in tailings dewatering back on track
}

\author{
Jürgen Hahn \\ BOKELA GmbH, Karlsruhe, Germany
}

SUMMARY: The filtration of tailings becomes more and more an indispensable part of the environmental management system of preparation plants. This requires powerful, reliable and economical filter technology. The BOKELA BoVac disc filter represents a new generation of high performance disc filters, which have set a new standard in the alumina industry, in the dewatering of coal slurries and which are operated in many applications of tailings dewatering such as gold/copper, zinc or gold/silver tailings (Hahn et al. 2015). This modern vacuum disc filter type is in approximately $80 \%$ of all applications the most economical technology for tailings dewatering - both in CAPEX and OPEX (Hahn et al. 2017 and 2014). However, running disc filters of older design are often not operated under optimal conditions and the results do not meet expectations because they are operated up to their capacity limit or beyond. In this case, it must be decided whether the operation target should be achieved with a new filters or by optimizing the existing filter system. To answer this question it is necessary to evaluate the potential for improvement and to have ideas as to which concrete measures are to be taken for an effective filter modification. The optimization of running filters with the BOKELA filter revamp program is a very economical alternative to new investments. With this revamping program inadequate performance, excessive maintenance and high operating costs of existing filters can be quickly and inexpensively eliminated by transferring advanced design features of the BOKELA disc filter design to disc filters of old design. Benefits include: a $30 \%$ to $135 \%$ increase in filtration capacity, improved cake moisture, improved filter operation and reduced maintenance. However, the costs amount only some $20 \%$ to $30 \%$ compared to a new investment.

Keywords: disc filter, filter optimisation, filter capacity, availability, cost reduction

\section{NEW INVESTMENT OR REVAMPING?}

The first step in deciding between a new filter installation and an existing filter plant optimisation is to verify the current performance and capability of the existing plant, and its improvement potential.

In many cases the revamping of running filtration plants improves the filter capability to such an extent that the required targets can be achieved as effectively and reliably as with new equipment. This requires that the revamping is informed by deep know-how and experience concerning the filtration process and filtration equipment. The upgrading of operating filter plants is realised much quicker and impairs the whole production process significantly less than the planning and implementation of new equipment. Capacity increases of $30 \%$ up to $135 \%$ can be achieved by revamping.

Investing in new equipment usually means a prolonged multistage procedure including; 
- a time consuming pre-engineering phase to specify and pre-plan rebuilding measures, to work out a specification of the new technology, etc.

- technology screening to identify the best suited technology available on the market, which often demands the performance of tests or trials

- OEM screening, calling for bids, to compare and evaluate the competitive offers with respect to technical and economic criteria, and to carry out negotiations

- complex engineering, since new equipment often requires modifications to the filter building or even a new building, both of which means comprehensive modifications to, or installation of completely new, piping, wiring, instruments, etc.

- potential for schedule slip in the installation of the new equipment through unforeseen delays, e. g. delayed delivery of one or more components

- overcoming of acceptance barriers by the operators and maintenance staff who also need a training and familiarisation period (with increased risk of malfunctions) to learn how to operate the new equipment well

- costs for additional peripheral equipment

- Applications and authorisations for financing the new investment.

Compared to this comprehensive and administratively heavy procedure, revamping existing filter equipment proceeds much more simply and directly, as numerous revamping projects have proven. The modernisation and upgrading measures of a filter revamping project normally cause less or no changes to the building, and the repercussions on the periphery of the filter plant are significantly reduced. The existing equipment is upgraded at the site and stays in place, so, the effort of pre-engineering, logistical planning, inquiring and ordering of supplementary peripheral equipment etc. are minimal compared to the installation of new equipment (Hahn et al. 2016).

In summary, the main advantages of a revamping process are;

- reduced planning and engineering effort

- compressed-schedule, fast realisation

- step-by-step engineering

- involvement of the owner's know-how and plant technical knowledge

- use of well-understood and operator-accepted equipment

- minimal costs for peripheral \& supplementary equipment

- coverage of costs by the maintenance budget

The optimisation of existing processes and equipment however, demands a fundamental understanding of the dependencies between the product to be filtered, the applied filtration process and the filter equipment used. Only substantial filtration know-how and expertise and the understanding of these dependencies allow the engineering of optimal solutions, and finally guarantee the improved performance. Against this background BOKELA has developed a successful concept to de-bottleneck and revamp existing filtration plants.

\section{BOKELA FILTER REVAMPING PROGRAMME - FILTER OPTIMISATION IN THREE STEPS}

On the basis of numerous filter revamping projects in nearly all industries, BOKELA has developed a special program for filter optimisation in three steps as shown in Figure 1. The three phases allows rigorous cost control, involvement of own plant technology and minimising risk. It is carried out with the know-how and the experience gained by upgrading of the drum, belt, disc and plate filters, filter presses, Niagara filters, Kelly filters etc. of nearly all OEMs.

\subsection{Diagnostic step}

In the first phase, the filtration behaviour of the product and the filter performance are examined in lab and field tests. This analysis of the existing state defines the real capacity of the 

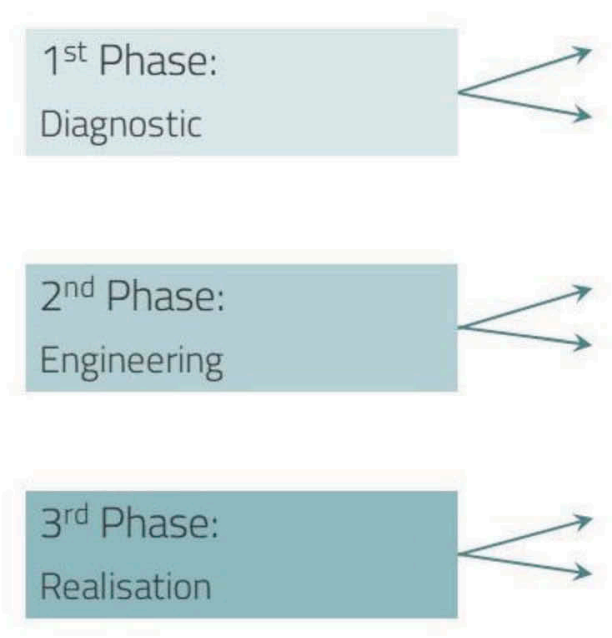

bench scale filtration tests and field tests on the running filters

presentation of modifications required, performance improvement and costs involved

engineering of filter parts subject to modification

manufacturing and supply of key parts for modification

filter modification on site supervised by BOKELA

start-up of the upgraded filter under the responsibility of BOKELA

Figure 1. General schedule of the filter optimisation program.

filtration plant and exposes the "bottle-necks". A "Test Report" gives very concrete details about the optimisation potential, and first estimates of costs and potential profitability of improvements.

\subsection{Engineering step}

In the second phase, modifications to the filtration plant for re-engineering are worked out, presented in a "Modification report" and discussed with the customer. According to these suggestions, it can be decided which of the recommended measures shall be selected. BOKELA then develops the required specifications and drawings.

\subsection{Realisation step}

The third phase - i.e. the modification works and the commissioning of the filtration plant starts when the specifications and drawings are checked. If the filtration plant consists of several filter units, only one filter unit will be modified initially. Most of the purchasing is organised by the customer, and the modifications are carried out in the customer's workshops as far as possible, while BOKELA supervises the modification work.

When the first filter modification is finished, the improved filter performance is determined in a test and compared to the calculated data from the tests of the first phase. All further filter units can be modified by the customer themselves in an analogous way.

\section{TYPICAL RESULTS AND TYPICAL COSTS OF FILTER REVAMPING}

Revamping of running filter plants can be realised faster and with significantly lower cost (ranging from $20 \%$ to $40 \%$ ), compared to the cost of a new filter. Typical modification measures and typical costs of a filter revamping are presented in Figure 2 and Table 1 using the example of a vacuum disc filter. Figure 2 shows filter components subject to modification and gives values of throughput and moisture improvement in disc filters for seed filtration in an alumina refinery reference. Typically, filter revamping can be performed with a small or large package of modification measures depending on the individual situation and client's objectives. Table 1 gives typical costs for these modifications in percent of the cost of a new filter. 

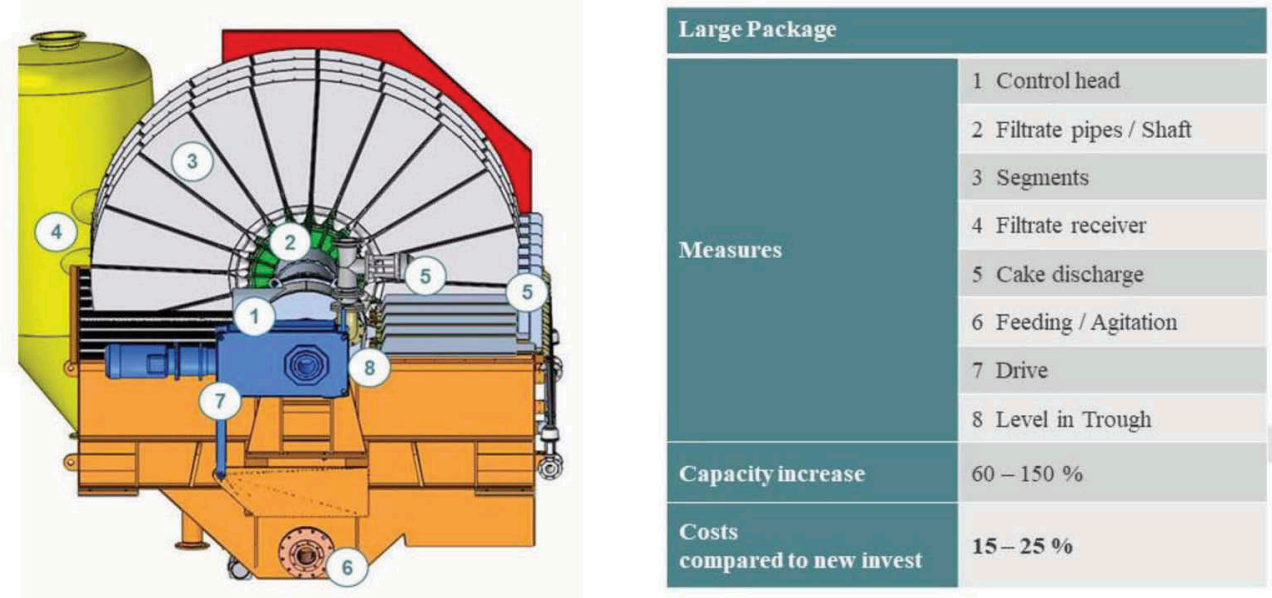

Figure 2. Typical modification measures and improvements for a disc filter revamping (given values refer to Al-hydroxide seed filtration).

Table 1. Typical costs for a disc filter revamping.

\begin{tabular}{lllll}
\hline & $\begin{array}{l}\text { Modification } \\
\text { measures (see } \\
\text { Figure 2) }\end{array}$ & $\begin{array}{l}\text { Throughput } \\
\text { increase } \\
\Delta \mathrm{ms}\end{array}$ & $\begin{array}{l}\text { Costs in percent of } \\
\text { costs for purchase of } \\
\text { new filter }\end{array}$ & $\begin{array}{l}\text { Costs in percent of costs for new } \\
\text { filter incl. installation and } \\
\text { commissioning }\end{array}$ \\
\hline $\begin{array}{l}\text { Small } \\
\text { package } \\
\begin{array}{l}\text { Large } \\
\text { package }\end{array}\end{array}$ & $1,4,5$ & $30-50[\%]$ & $25[\%]^{*}$ & approx. 10 [\%]** \\
\hline
\end{tabular}

* Only costs in percent of costs for new filter unit.

** Total costs of a new filter investment amount to 3 to 4 times the price of the new filter due to the additional costs for building, piping, auxiliary units and engineering.

This comparison is based on the total cost of a new filter finally amounting to 3 to 4 times the price of the new filter itself due to the additional necessary costs for building, piping, auxiliary units and engineering.

\section{CASE STUDIES - EXEMPLARY REFERENCES}

BOKELA is the No. 1 expert in filter revamping world-wide and has carried out a multitude of revamping projects in many industries on a variety of filter types of numerous OEMs. A main focus of BOKELA's revamping activities has been the alumina industry with many modifications of vacuum disc, pan and drum filters operated for seed filtration, product filtration or red mud filtration. Two exemplary case studies are briefly discussed below.

\subsection{Revamping of disc filters for seed filtration}

In an Alumina refinery, 5 disc filters of type A with 8 discs and $160 \mathrm{~m}^{2}$ filtration area each, and 3 disc filters of type $B$ with 3 discs and $110 \mathrm{~m}^{2}$ filtration area each were operated for seed 
filtration. To improve the plant capacity BOKELA was requested to optimize these filters by a filter re-vamping.

Target of the client was:

- increase of the total plant capacity

- de-bottlenecking of the existing seed disc filters instead of new filters

Expectations with respect to the optimized disc filters were:

- solids throughput increases by the amount of two additional filters of type A

- moisture content may not increase

- secure and complete cake discharge

- improved filter availability

- more spare capacity

- reduced filter operating costs

To provide for these improvements one (1) filter of type A was modified according to the "large package" modifications (see Figure 2 and Table 1), comprising the following measures:

- new filter barrel (9 discs)

- new high performance segments (20 per disc)

- higher slurry level in the filter trough

- modifications to control head

- new control plate

- new filter drive

- new snap blow system for cake discharge

- filter operation without overflow

Four (4) filters of type A were modified according to the "small package" modifications (see Figure 2 and Table 1) comprising the following measures:

- higher trough level

- new control and wear plate

- new snap blow system for cake discharge

The results of these modifications in terms of operating and performance data before and after modifications are shown in Table 2. Figure 3 shows a modified type A disc filter in operation with highly effective cake discharge.

The data in Table 2 illustrate that a targeted capacity increase of nearly two times the additional capacity of one (1) type A disc filter could be achieved with the modified filters. The filter which received large package modifications has about $75 \%$ more solids capacity after revamping while the four (4) filters which were modified with small package modifications show a solids capacity increase of $30 \%$ each. In total, the surplus capacity of the modified filters is equivalent to the capacity of two old type A disc filters. Cake moisture improved from $20.1 \mathrm{wt}-\%$ to $14.5 \mathrm{wt}-\%$ and $19.5 \mathrm{wt}-\%$.

Table 2. Operating and performance data of seed disc filters of type A before and after modifications.

\begin{tabular}{|c|c|c|c|c|}
\hline $\begin{array}{l}\text { operating and performance } \\
\text { data of type A seed disc filters }\end{array}$ & & before & $\begin{array}{l}\text { after modifications with } \\
\text { large package ( } 1 \text { filter unit) }\end{array}$ & $\begin{array}{l}\text { after modifications with } \\
\text { small package (4 filter } \\
\text { units) }\end{array}$ \\
\hline filter speed & [rpm] & 1 & 2.0 & 1.35 \\
\hline cake moisture content & {$[\%]$} & 20.5 & 14.5 & 19.5 \\
\hline specific slurry flow & $\begin{array}{l}{\left[\mathrm{m}^{3} /\right.} \\
\left.\mathrm{m}^{2} \mathrm{~h}\right]\end{array}$ & 1.7 & 3.0 & 2.2 \\
\hline specific solids rate & {$\left[\mathrm{t} / \mathrm{m}^{2} \mathrm{~h}\right]$} & 3.0 & 5.4 & 4.0 \\
\hline cake discharge & {$[\%]$} & 80 & 95 & 95 \\
\hline
\end{tabular}




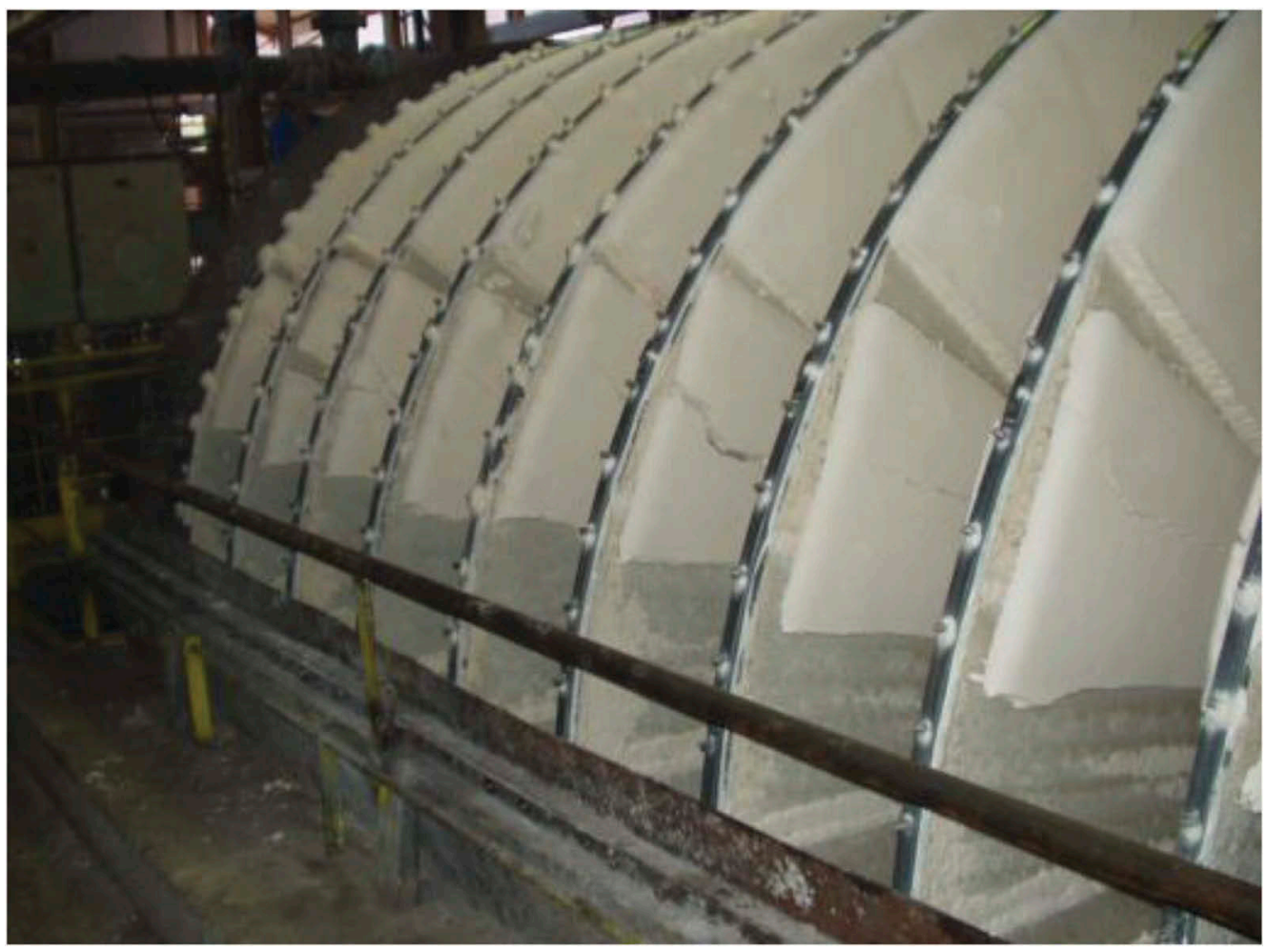

Figure 3. Complete cake discharge of a type A disc filter after revamping with "large package" modifications.

The cost of modifying these 5 disc filters was less than $25 \%$ of the purchase and installation cost of two (2) additional type A disc filters.

\subsection{Revamping of disc filters for coal ultrafines filtration}

This coal disc filter optimisation project at the Saraji coal washery in the Bowen Basin, Australia was carried out together with the experts of Saraji. The original filters at the site were two Denver disc filters + (1 x EIMCO Belt Filter).

The disc filters were installed 30 years ago and had

- 14 discs each with $4.2 \mathrm{~m}$ disc diameter

- 12 sectors per disc (s/steel) - $40 \mathrm{~kg}$ per sector (Figure 4)

- total filter area: $280 \mathrm{~m}^{2}$ per filter

- filter cloth: s/steel mesh

- air agitation (formerly mechanical agitation)

- filters operated with slurry overflow

Typically the filters rotated quite slowly at around 0.5 to $1 \mathrm{rpm}$ and were fed with more fine coal slurry than they could process with the overflow reporting back to the feed system. The filters were also quite maintenance intensive because the original equipment designers did not recognise the flaws in their design. Routine access to the filters was cumbersome due to the need to build temporary access. And on top of the temporary access awkward maintenance 

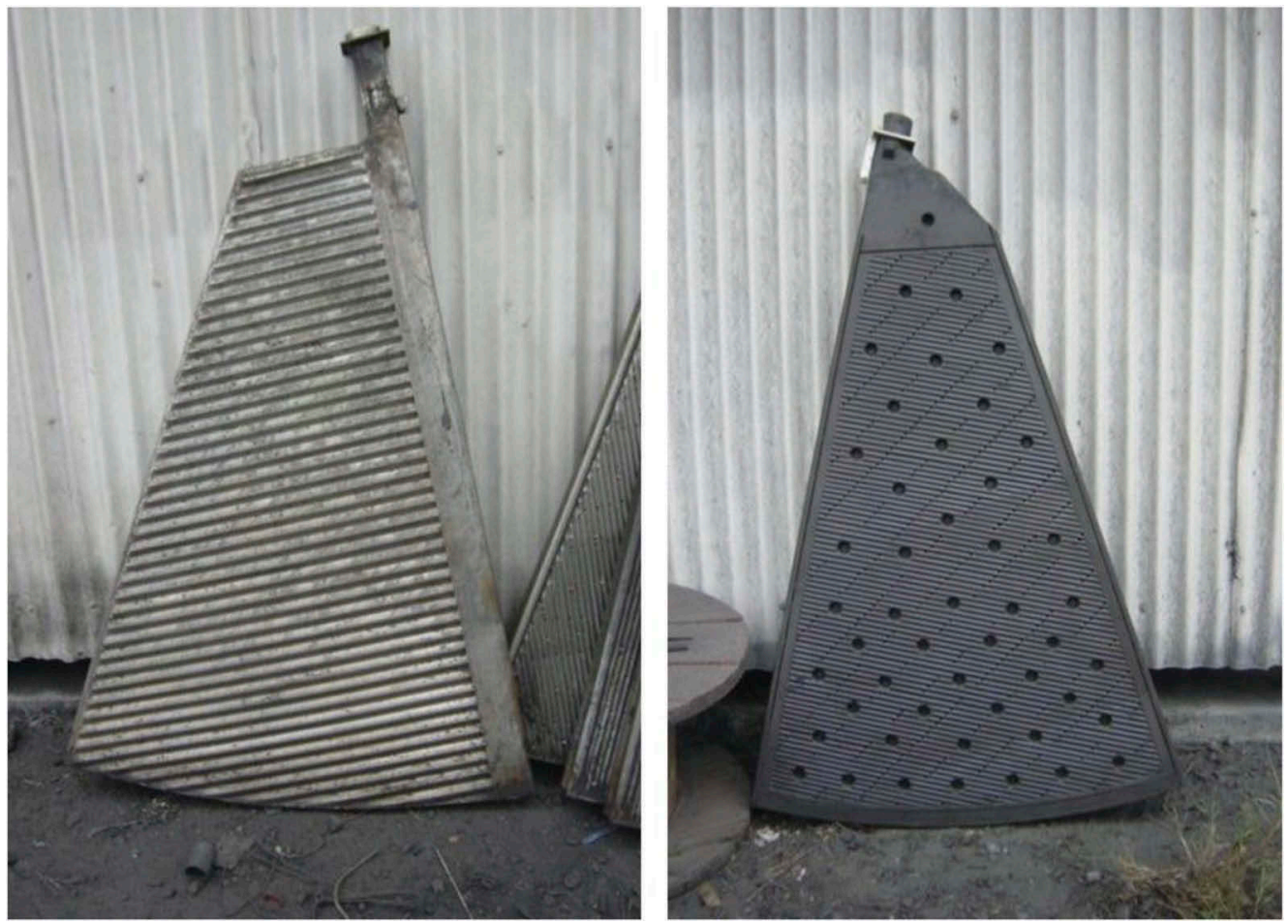

Figure 4. Old and heavy (40 kg) filter segments (12 segments per disc).

activities such as replacement of heavy segments weighing at least $40 \mathrm{~kg}$ (90lb) was expected. This of course leads to maintenance being delayed until the filtering process is severely affected.

\subsubsection{Project Brief from the Client}

The client expected the following filter improvements from the revamping project:

- increase filtration capacity by approx $100 \%$ (as per testwork assessment)

- maintain or improve total cake moisture

- (target for coal moisture + free moisture = low 20's)

- improve operation (automated)

- reduce maintenance requirements

\subsubsection{Implementation of Modifications}

The following disc filter modifications were implemented by BOKELA to meet the design brief:

- 2 independent filters (each 7 discs) to replace each Denver filter, achieved by dividing trough with a new wall

- new filter shafts/barrels with removable filtrate pipes (Figure 6)

- new low wear sectors; 20 per disc, approx $19 \mathrm{~kg}$ each (Figure 5)

- new bayonet segment fixing for fast change out

- new low wear control heads

- new drive system (motor/slip-on gear box)

- new snap blow system

- increase of slurry level

- automatic level control so there is no overflow recirculation required 


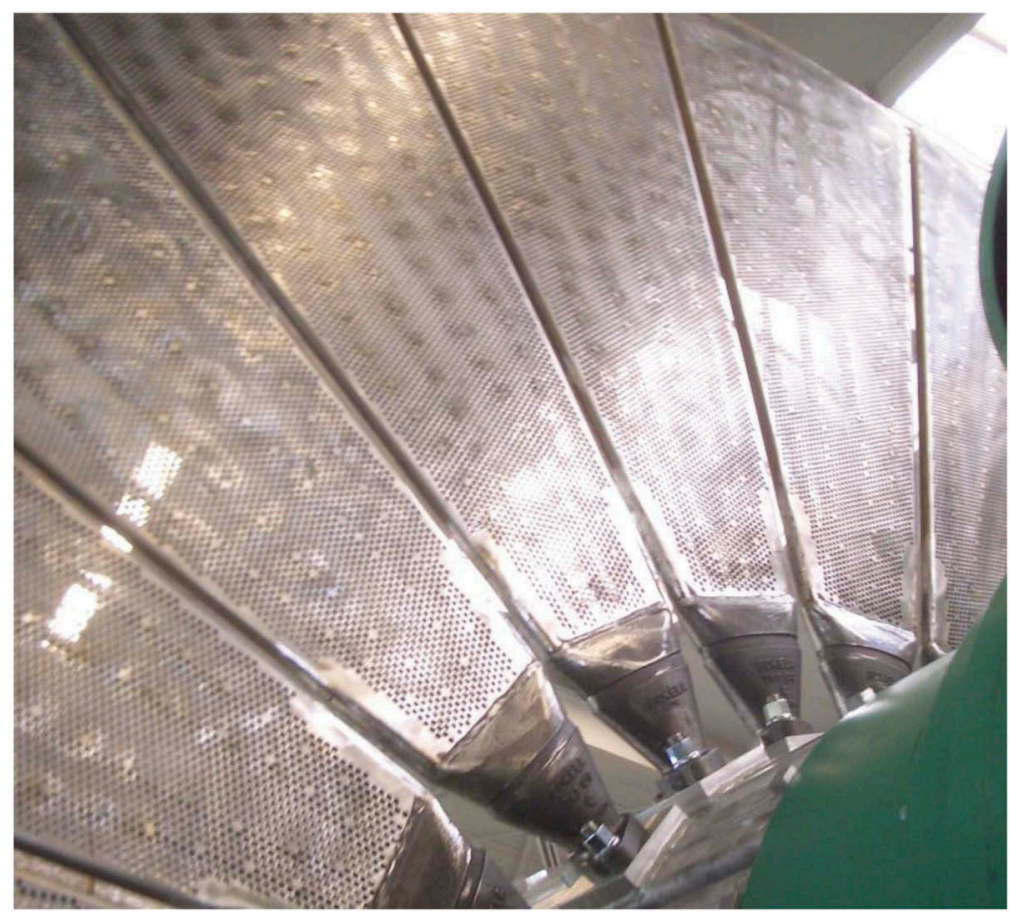

Figure 5. New filter segments (19 kg per segment, 20 segments per disc).

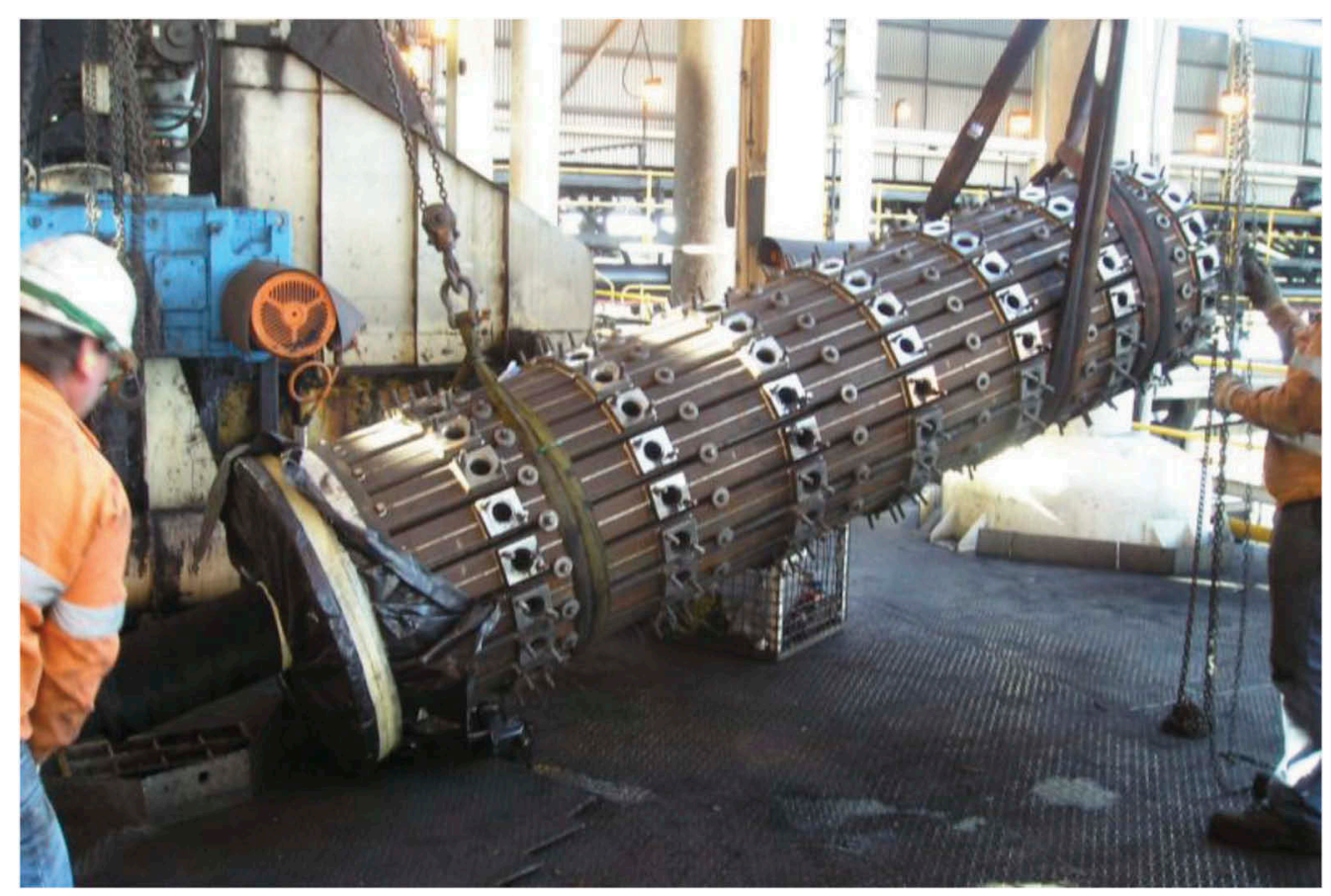

Figure 6. Lifting of new filter barrel. 
- relocation of feed pipes

- no trough agitator required

- new permanent walkways

- modification of filtrate receiver to reduce carryover.

\subsubsection{Design and Performance of the Coal Filters after the Revamping}

The revamped filters run with up to $3 \mathrm{rpm}$ and have $100 \%$ more filtration capacity as can be seen from Table 3. Figure 7 shows one of the upgraded filters.

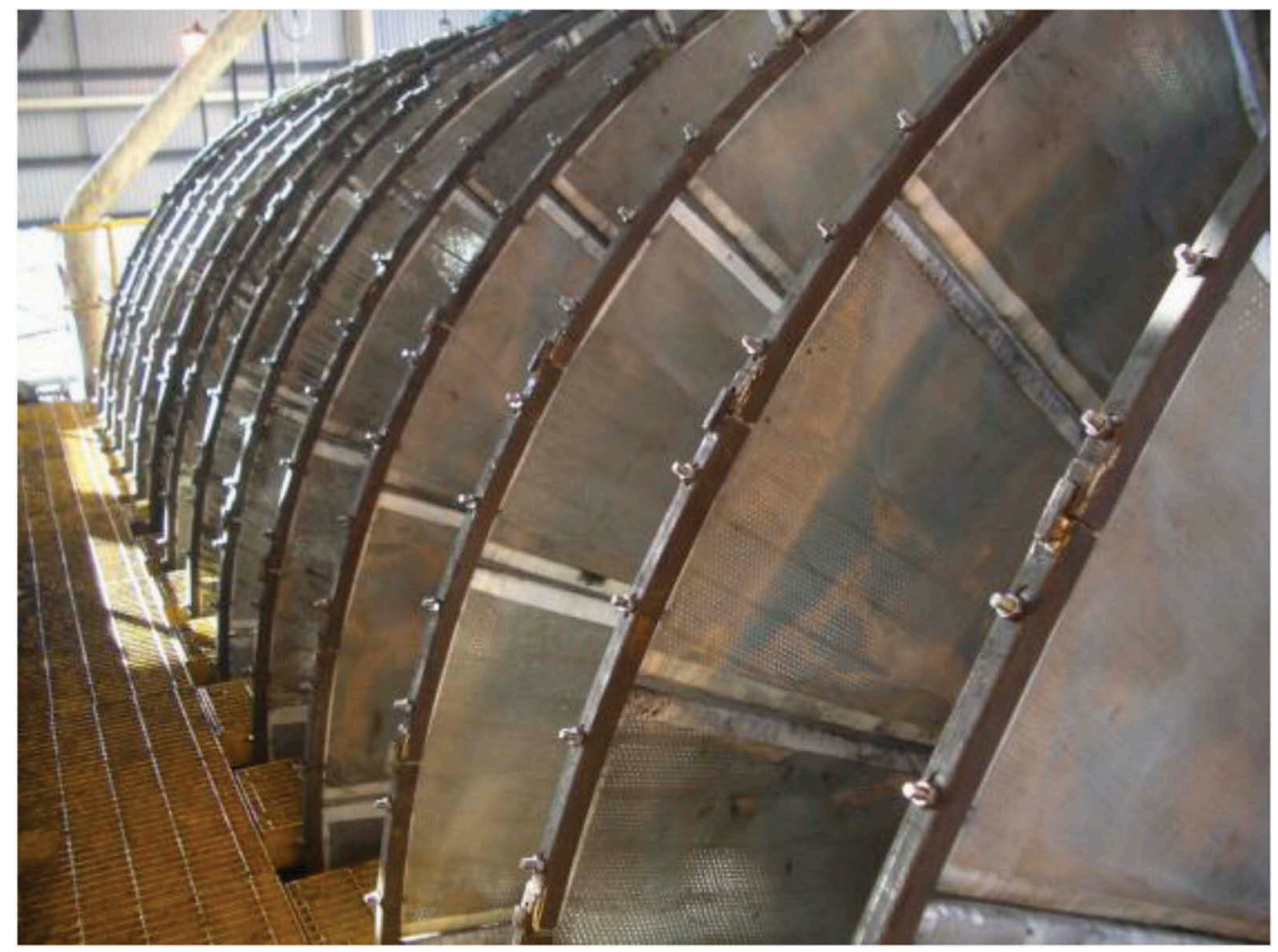

Figure 7. Revamped filter with improved access along the filter by permanent walkways.

Table 3. Filter data and filter performance before and after revamping by BOKELA.

\begin{tabular}{lll}
\hline & Before & After \\
\hline disc diameter & $4.2 \mathrm{~m}$ & $4.2 \mathrm{~m}$ \\
number of discs & 14 & $2 \times 7$ \\
segments per disc & 12 & 20 \\
filter area per disc & $20 \mathrm{~m}^{2}$ & $22 \mathrm{~m}^{2}$ \\
segment fixing & bolted (tie rod) & bayonet fixing \\
filter speed & up to $0.75 \mathrm{rpm}$ & up to $\mathbf{3} \mathbf{~ r p m}$ \\
total area & $280 \mathrm{~m}^{2}$ & $2 \times 154 \mathrm{~m}^{2}$ \\
trough design & Air agitated trough & common trough with feed and disc agitation \\
volumetric flow & $220 \mathrm{~m}^{3} / \mathrm{h}$ & $\mathbf{2} \times \mathbf{2 3 0} \mathbf{~ m}^{3} / \mathbf{h}$ \\
tonnage & $76 \mathrm{t} / \mathrm{h}$ & $\mathbf{2} \mathbf{8 0 ~ t / h}$ \\
specific throughput & $270 \mathrm{~kg} / \mathrm{m}^{2} / \mathrm{h}$ & $\mathbf{5 2 0} \mathbf{~ k g} / \mathbf{m}^{2} / \mathbf{h}$ \\
\hline
\end{tabular}




\section{CONCLUSION}

Filter optimization with sensible modifications is a viable alternative to increase filter capacity and/or improve cake moistures. It can replace the requirement to purchase new filters plus the infrastructure for the new filter (building, piping, electrics, auxiliaries etc $=3 \mathrm{x}$ filter cost). The optimization of filters requires a comprehensive understanding of all aspects of filter design and technology and a well founded knowledge of dewatering practice and hydrodynamics. Improving performance of filters can not be done by just tackling single 'soft spots and bottlenecks' of the filter itself. It rather requires a 'holistic' expert approach which takes into consideration the complex nature of design and performance parameters. Increasing the filter capacity is not the only benefit of filter re-vamping, an optimised filter design also improves the product quality and reduces operating and maintenance costs. Furthermore, an optimised filter design increases the filter flexibility and filter availability and leads to a significant improvement in filter operational control. Last but not least, the operators can work with familiar equipment.

\section{ACKNOWLEDGEMENTS}

Thank you to our clients and their staff for their great cooperation and input into the revamping projects featured in this report.

\section{BIBLIOGRAPHY}

Hahn et al. 2017 - Hahn, J., Egger, A. (2017) 'Report on Tailings Dewatering with High Performance Disc Filters' 12th International Symposium on Mining with Backfill, 19-22 February, Denver, USA

Hahn et al. 2016 - Hahn, J., Viet, Ch. (2016) 'Three Steps to Improved Filtration Performance and Reduced Cost in Times of Limited Capital' ICSOBA 2016, 34th Conference \& Exhibition, 3-6 October, Quebec, Canada

Hahn et al. 2015 - Hahn, J., Bott, R., Langeloh., (2015) 'Size Matters, Weight Too - Disc Filter Design For the Future' proceedings of 10th AQW 2015, Perth, Australia.

Hahn et al. 2014 Hahn, J., Bott, R., Langeloh. T., (2014) 'Economical dewatering of tailings for mine backfill with high performance disc filters' proceedings of the 11th International Symposium on Mining with Backfill, 20-22 May 2014, Perth Australia.Conference papers 